\title{
Ganglioneuroma de suprarrenal
}

\section{Adrenal ganglioneuroma}

Rafael Rabello lista Mira, TCBC-MG'; Tereza Cristina Bernardo Fernandes, TCBC-MG²; Ivan Cesar Said Resende, tCBC-MG²; José Gabriel Timóteo Tostes, TCBC-MG²; Jean Khoury José3

\section{INTRODUÇÃO}

G anglioneuromas são tumores raros, benignos e bem diferenciados originados da crista neural. Pertencem ao grupo dos tumores neurogênicos que também inclui o neuroblastoma. O retroperitônio é sua localização mais comum seguida do mediastino posterior, com uma pequena proporção na suprarrenal. A maioria ocorre em adultos acima de 40 anos.

Relatamos o caso de uma jovem de 24 anos de idade com dor lombar e massa na glândula suprarrenal direita.

\section{RELATO DO CASO}

Paciente com 24 anos, sexo feminino, leucodérmica, estudante, apresentando queixa de dor lombar à direita, com início a cerca de um ano. De caráter contínuo e progressivo, sem irradiação, em aperto, com piora à deambulação. Alívio ao uso de analgésicos comuns. Nega emagrecimento, febre ou sintomas urinários. Exame físico sem alterações; sem queixas à palpação abdominal. Solicitados então hemograma e radiografia de abdome: ambos sem alterações.

A ultrassonografia de abdome evidenciou imagem hipoecóica junto do pólo superior do rim direito, medindo $6 \times 3 \mathrm{~cm}$, sugestiva de massa de suprarrenal. A tomografia de abdome evidenciou lesão expansiva com densidade de partes moles, homogênea, de contornos regulares e limites definidos, medindo $6 \times 6 \mathrm{~cm}$ na topografia de suprarrenal direita (Figura 1).

Com o diagnóstico de massa na suprarrenal, a investigação bioquímica foi realizada, com dosagens de cortisol livre, testosterona, DHEA, ACTH, metanefrina, normetanefrina e aldosterona, todas normais.

Uma vez tratando-se de lesão não-funcionante, com diâmetro aferido pelos meios de imagem superior à $6 \mathrm{~cm}$ indicou-se a ressecção da tumoração por via aberta anterior. No per operatório foi evidenciada lesão bem definida, encapsulada, de fácil dissecção em relação às estruturas adjacentes. O pós operatório evoluiu sem intercorrências, tendo os sintomas abdominais desaparecido.

O exame anátomo-patológica mostrou uma formação nodular, amarelada, firme, capsulada, pesando 108g, medindo $8 \times 6,5 \times 5 \mathrm{~cm}$. O diagnóstico histopatológico mostrou arquitetura tecidual compatível com ganglioneuroma (Figura 2).

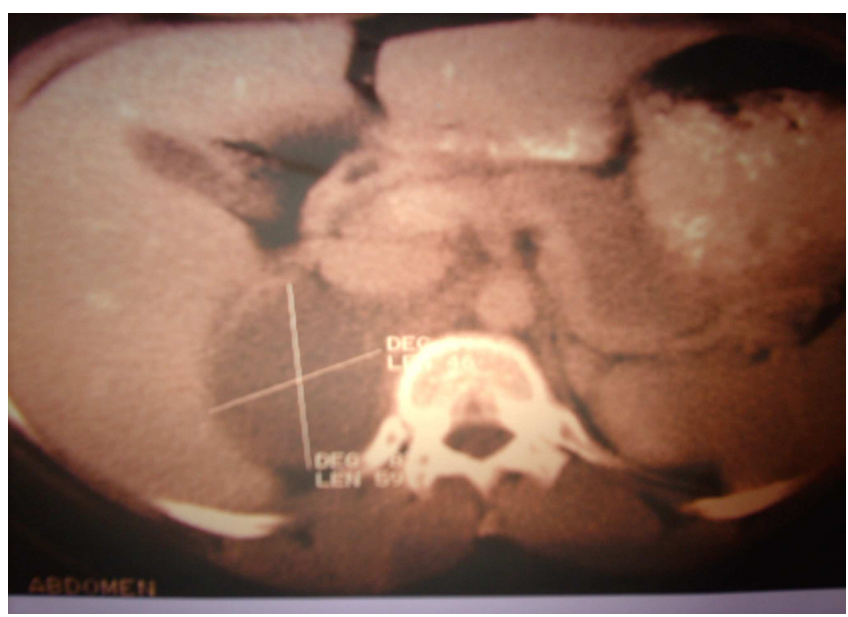

Figura 1 - Tomografia de abdome evidenciando massa em to pografia de supra-renal direita.

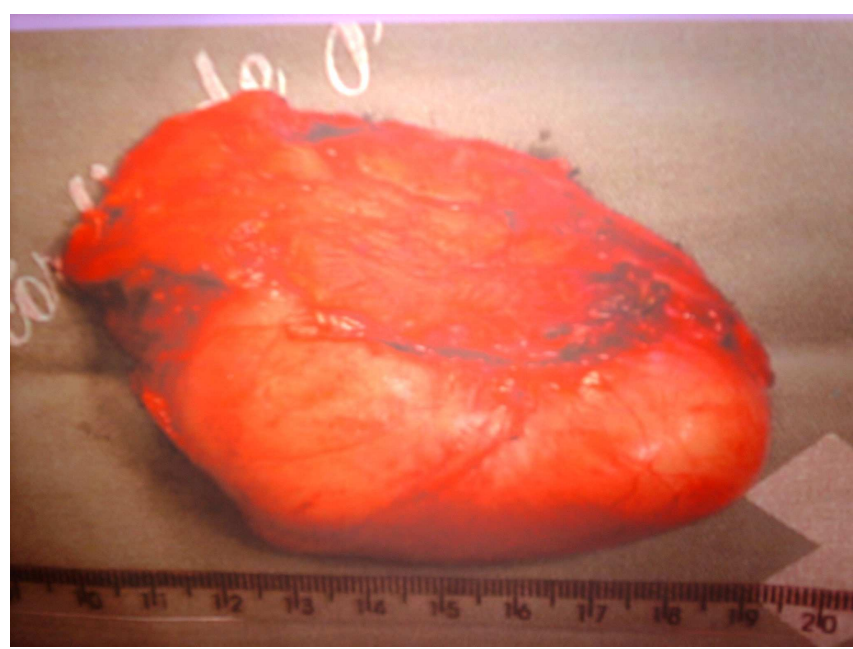

Figura 2 - Espécime cirúrgico.

Trabalho realizado na Santa Casa de Misericórdia de Juiz de Fora/MG

1. Cirurgião geral e ex-residente da Santa Casa de Misericórdia de Juiz de Fora/MG; 2. Cirurgião geral da Santa Casa de Misericórdia de Juiz de Fora/MG; 3. Urologista e ex-residente da Santa Casa de Misericórdia de Juiz de Fora/MG. 


\section{DISCUSSÃO}

O ganglioneuroma é uma neoplasia benigna e rara, proveniente do sistema neuroendócrino simpático (crista neural). É composto de células ganglionares maduras e células de Schwann ${ }^{1}$. Em alguns casos, se mantém como o estágio final da maturação espontânea de certas neoplasias pouco diferenciadas, como o neuroblastoma e o ganglioneuroblastoma ${ }^{2}$.

Sua distribuição anatômica mais frequente é o mediastino posterior, seguida pelo retroperitônio, paralela à cadeia ganglionar simpática. Apenas uma pequena proporção têm sua origem na glândula suprarrenal (cerca de $15 \%)$, ocorrendo mais comumente em crianças e adulto jovens ${ }^{1}$. A incidência exata não é conhecida. Segundo Huang et al., corresponde a $3,8 \%$ dos tumores da suprarrenal ${ }^{3}$. Predomina no sexo feminino $(3: 2)^{4}$.

São tumores de diagnóstico diferencial difícil devido à falta de características de imagens específicas.
Crescem lentamente e podem atingir grandes dimensões, tornando-se clinicamente evidentes devido à compressão de estruturas adjacentes. Usualmente são silenciosos, incidentalmente diagnosticados por exames de imagem realizados para outros fins ${ }^{5}$, não são hipersecretores de catecolaminas ou hormônios esteróides ${ }^{1}$ e, na muitas vezes, não são considerados no diagnóstico dos incidentalomas nos adultos.

As lesões podem ser ressecadas e, apesar do diagnóstico pré-operatório ser difícil devido à falta de exames específicos ${ }^{5}$, o prognóstico é favorável. Quando diagnosticados após os 10 anos de idade1, estes tumores podem recidivar. Focos metastáticos podem ser encontrados em linfonodos 4 .

Trata-se, portanto, de tumor benigno, existindo dificuldade em relação ao seu diagnóstico pré-operatório. Deve ser considerado no diagnóstico diferencial de tumores localizados no mediastino posterior e retroperitônio.

\section{A $B$ S $S$ T $R$ R A C $T$}

Ganglioneuromas are rare, benign tumors arising from neural crest tissue. Their most frequent location is the posterior mediastinum, followed by the retroperitoneum. Only a small proportion are adrenal in origin. The authors report a case of a 24-year-old woman with inespecific symptoms of low back pain and presenting with an adrenal mass. An adrenalectomy was performed and the diagnosis of ganglioneuroma was confirmed.

Key Words: Ganglioneuroma. Neoplasms. Neural crest. Adrenal glands. Zona fasciculata.

\section{REFERÊNCIAS}

1. Arredondo Martínez $F$, Soto Delgado $M$, Benavente Fernández $A$, Basquero González B, Zurera Cosano A, Linares Armada R. Adrenal ganglioneuroma. Report of a new case. Actas Urol Esp. 2003;27(3):221-5.

2. Nelms JK, Diner EK, Lack EE, Patel SV, Ghasemian SR, Verghese M. Retroperitoneal ganglioneuroma encasing the celiac and superior mesenteric arteries. Scientific World Journal. 2004;4:9747.

3. Huang SP, Chou YH, Wu MT, Chai CY, Tsai HN, Li CC, et al. Adrenal tumors: 10-year experience at Kaohsiung Medical University Hospital and literature review. Kaohsiung J Med Sci. 2002;18(9):450-8.

4. Singh D, Singh A, Prabhakar BR, Arora R, Jain S, Hara GS, et al. Ganglioneuroma of the adrenal gland. Indian J Surg. 2003;65(5):436-8.
5. Fujita T, Maru N, Iwamura M, Tojo T, Yoshida K, Baba S. Two cases of ganglioneuroma. Hinyokika Kiyo. 2003;49(2):107-10.

Recebido em 01/03/2007

Aceito para publicação em 08/05/2007

Conflito de interesse: nenhum

Fonte de financiamento: nenhum

\section{Como citar este artigo:}

Mira RRL, Fernandes TCB, Resende ICS, Tostes JGT, José JK. Ganglioneuroma de suprarrenal: relato de caso. Rev Col Bras Cir. [periódico na Internet] 2012; 39(1). Disponível em URL: http:// www.scielo.br/rcbc

Endereço para correspondência:

Rafael Rabello Lista Mira

E-mail:rrlmira@gmail.com 